\title{
Machine Learning Based Behavioral Modification
}

\author{
Ani Cahyadi, Abduk Razak, Husni Abdillah, Farid Junaedi, Sri Yunita Taligansing
}

\begin{abstract}
To build up a particular profile about a person, the study of examining the comportment is known as Behavior analysis. Initially the Behavior analysis is used in psychology and for suggesting and developing different types the application content for user then it developed in information technology. To make the applications for user's personal needs it becoming a new trends with the use of artificial intelligence (AI). in many applications like innovation to do everything from anticipating buy practices to altering a home's indoor regulator to the inhabitant's optimal temperature for a specific time of day use machine learning and artificial intelligence technology. The technique that is use to advance the rule proficiency that rely upon the past experience is known as machine learning. By utilizing the insights hypothesis it makes the numerical model, and its real work is to infer from the models gave. To take the information clearly from the data the methodology utilizes computational techniques.
\end{abstract}

Keywords : Behaviour analysis; psychology; machine learning; artificial intelligence.

\section{INTRODUCTION}

To make the computer in such a way that it can evolve by itself the machine learning develop the solution for create the self working techniques. Machine learning is the subcategory of artificial intelligence. To determine the rules that be incorporated to adjust software application by using machine learning and artificial intelligence the user's actions and activities can be analyzed. It also analyzes comportment and daily routine of a person

To enhance the treatment accuracy and efficiency it will be possible in the next decade to develop such micro biosensors, devices and mobile applications that give more significant information to encourage research and department. In term of heath monitoring this type of data give significant bits of knowledge to the person. It also provides help to lessen the cost of complete human healthcare. It is possible if these plan and medicine followed by more patients.

The area that are related to prevention, treatment and ailment identification are using behavioral modification for starting many relevant applications and prevention of the

Revised Manuscript Received on July 22, 2019

* Correspondence Author

Ani Cahyadi, Faculty of Education and Training, State Islamic University of Antasari, South Borneo, Indonesia. E-mail: anicahyadi@uin-antasari.ac.id

Abduk Razak, Sekolah Tinggi Ilmu Ekonomi Enam Enam, Indonesia.

Husni Abdillah, Universitas Negeri Malang, Indonesia

Farid Junaedi, Universitas Negeri Malang, Indonesia

Sri Yunita Taligansing, Faculty of Tarbiyah and Teacher Training, IAIN Sultan Amai Gorontalo, Indonesia data. Some areas like in smoking session for helping the people to understand the behavior make invigorating changes and understand hand-to-mouth gestures many software like data-analytics B2B2C software platform offered by companies. This software is based on machine learning. In second example the patient can use Skin Vision application in order to check the skin cancer it is skin cancer risk app.

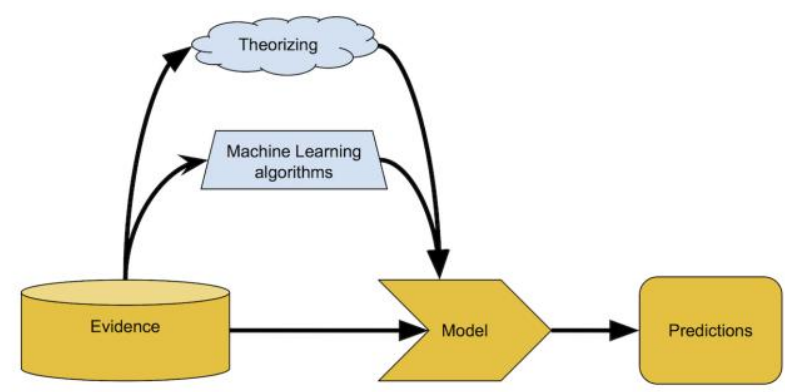

Figure 1: Machine learning model creation

\section{RELATED WORK}

To clarify the comportment of a subject to build up principles and models about an person the Behavior analysis was initially used in psychology. in information technology with the use of computer program the interaction of users has been increased in couple of years [2]. In staring of Behavior analysis it was use for build up a profile or content of a client to sell product and when it want to determine the profile of customers which deal in future. Basic recommender systems are the first solution that it can use. But it was not use any technique which is based on machine learning, this system was based on some specific rules. Using machine learning algorithm to make a list of past behavior the recommendation build. Cherry, s.d. and Tim Jones in 2013 [10] described that it is actualized into search for a social tag or contents, and for e-commerce websites they replaced the old engines.

\section{TYPES OF MACHINE LEARNING}

The main two types of machine learning are Supervised are Unsupervised. There is some more machine learning are Semi-Supervised, Deep learning, Evolutionary learning and Reinforcement are discussed below [3]: 


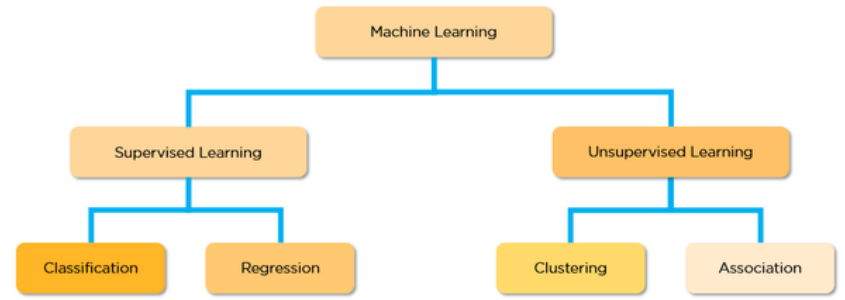

Figure 2: Types of Machine learning

1. Supervised machine learning-

This type of machine learning provides a training data set. As depend on training data set this machine learning method give response accurately to all inputs that are feasible. Supervised Learning is also called as Learning from examples [4]. There are two types of supervised machine learning are regression and classification.

\section{Unsupervised machine learning}

This type of machine learning finds the similarities between the data that is input. On the basis of these similarities, this technique us for data classification. This is often called as [5] estimation of density. on the basis of similarities it have clustering that make clusters.

Some other types of machine learning are:

\section{Semi-supervised machine learning}

This technique is considered as the class of supervised learning techniques. For training this machine learning uses unlabelled data [6]. It is the learning that exists between supervised learning and unsupervised learning. The supervised learning has labeled data and unsupervised learning has unlabelled-data.

\section{Reinforcement machine learning}

Behaviourist psychology supports this type of machine learning. There is using and algorithm that denote that answer is wrong but it does not tell how to correct that answer. Until find the correct answer this algorithm performs many tests [7]. In this learning improvement is not possible.

\section{Evolutionary machine Learning}

This type of learning shows that to make the progress how the biological organisms are adapted [8]. For checking the accuracy of the solution idea of fitness is used.

\section{Deep machine learning}

To optimize the result of the work this learning uses back propagation for study the model parameters [9]. With several processing layers this learning uses deep graph, this graph is made with several transformation that can be linear and nonlinear.
Table 1: comparesion of the three classification algorithms

\begin{tabular}{|l|l|l|}
\hline \multicolumn{1}{|c|}{ Algorithms } & \multicolumn{1}{c|}{ Advantages } & \multicolumn{1}{c|}{ Disadvantages } \\
\hline Bayes & $\begin{array}{l}\text { - Fast and converge quickly } \\
\text { - Less training data } \\
\text { - Memory Usage Low }\end{array}$ & $\begin{array}{l}\text { - Don't take in account } \\
\text { interactions between the } \\
\text { features }\end{array}$ \\
\hline Decision Trees & $\begin{array}{l}\text { - Easy to interpret } \\
\text { - Handle interaction } \\
\text { - Memory Usage Low }\end{array}$ & $\begin{array}{l}\text { - Easily over fit } \\
\text { - Speed : medium }\end{array}$ \\
\hline SVMs & $\begin{array}{l}\text { - High accuracy } \\
\text { - Good for text classification }\end{array}$ & $\begin{array}{l}\text { - Memory-intensive } \\
\text { - Hard to interpret }\end{array}$ \\
\hline
\end{tabular}

\section{PROCESS}

To analyze the behavior of a person it is very difficult to create a process from starting to develop a complete solution of a particular problem. The steps including in the process are as follows:

1. Understanding the problem: at initial stage it is very important to understand what the problem in reality and how the solution of that problem looks like.

2. Understanding the data: if the data is related to our present problem then it should understand what the amount of data is, what is the availability and quality of the data.

3. Preprocessing of data: it should consider that what data is more important, to increase the quality and modeling of data it should find the best solution.

4. Modeling: in this step it should choose the best model and method to find the best solution of current problem.

5. Data evolution: if the choosing model completes the needs then it should answer the questions.

6. Deployment: it should develop a model that has validation in real applications and this step also include the details about deployment of model.

\section{CREATION OF THE MODEL}

To predict the function of a user the model uses Bayes Network Classifier. KNIME have many classification algorithms and it provides several extensions. By using Weka (3.7) KNIME library with machine learning algorithms the model is developed. Into the node repository the weka node are available, after library installation. The following figure shows the modification of The BayesNet node classifier. 


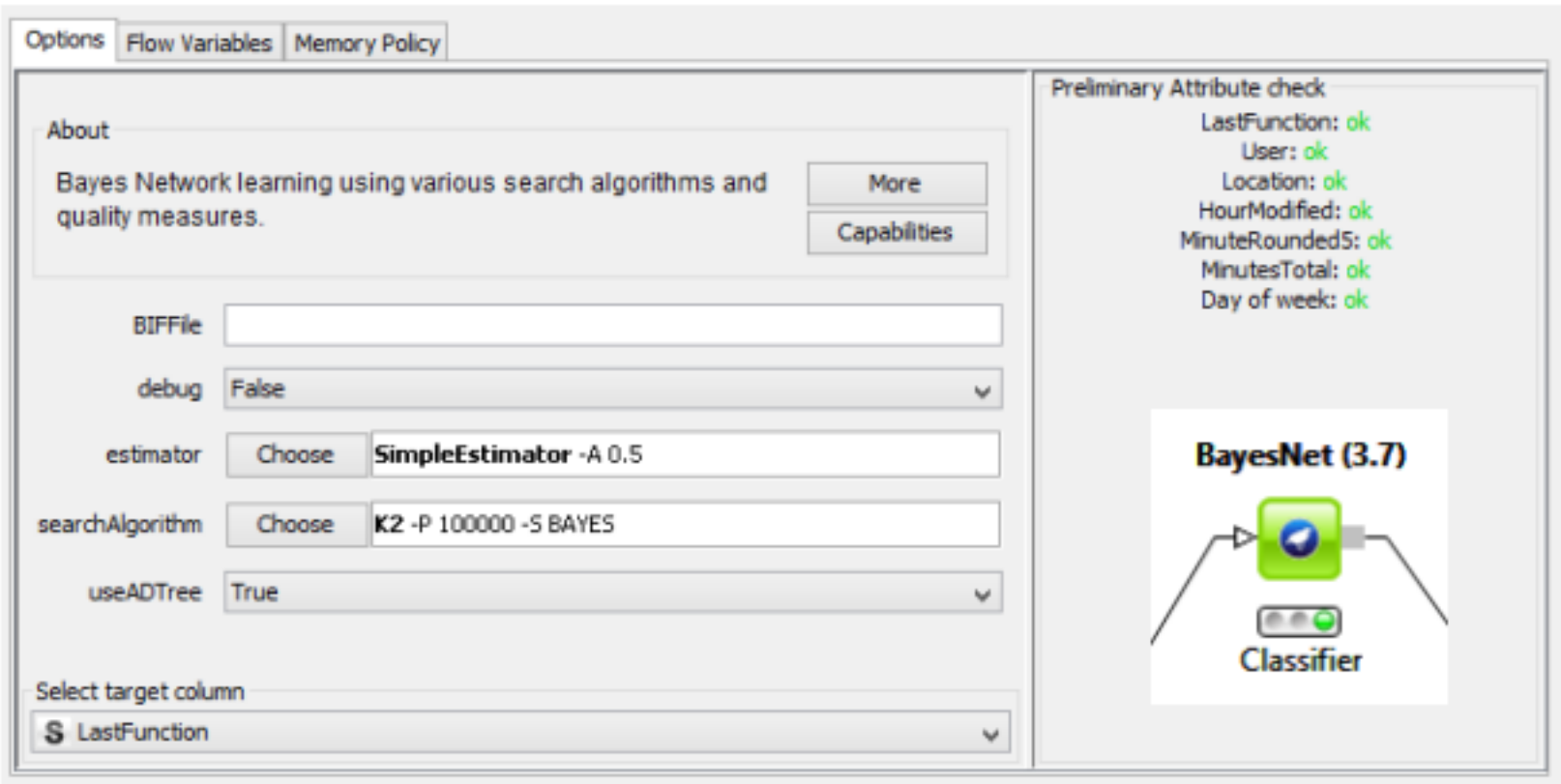

Figure 3-modification of BayesNet

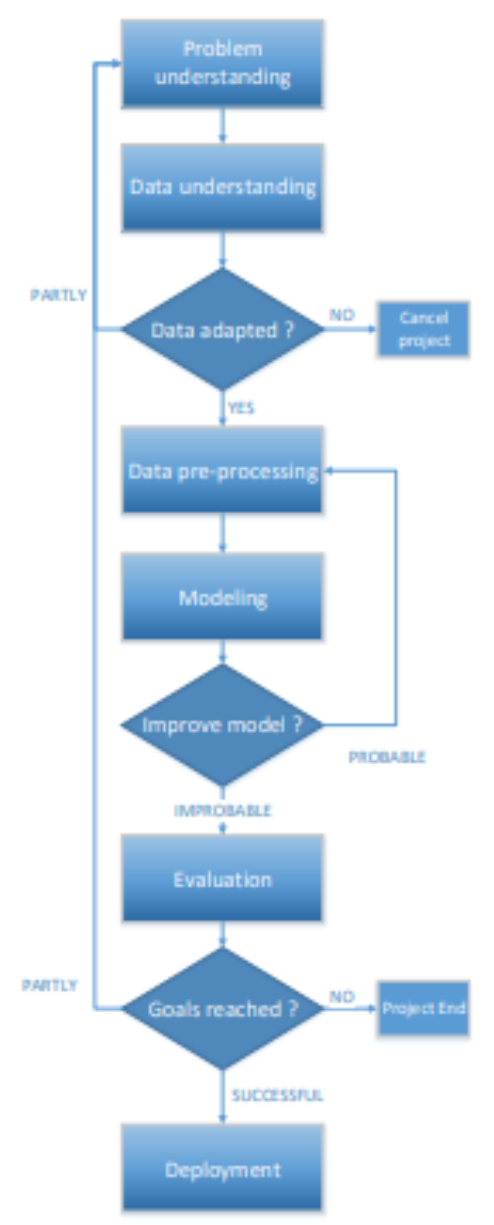

Figure 4: data analysis processing 


\section{IN BEHAVIOR CHANGE THE CHALLENGES THAT ARE FACNING INTERPRETATION AND SYNTHESIS}

Table 2: behavior change challenges

\begin{tabular}{ll}
\hline \multicolumn{1}{c}{ Challenge } & \multicolumn{1}{c}{ Solution } \\
\hline $\begin{array}{l}\text { Research methods: Diversity of research methods and topics, } \\
\text { and inconsistency and incompleteness in reporting of study } \\
\text { methods and findings }\end{array}$ & $\begin{array}{l}\text { Development and application of an ontology of } \\
\text { behaviour change interventions }\end{array}$ \\
$\begin{array}{ll}\text { Human limitations: Insufficient human resources to undertake } \\
\text { reviews and syntheses in a timely manner given the volume of }\end{array}$ & $\begin{array}{l}\text { Use of automated literature searching and study } \\
\text { findings and increasing rate of evidence accumulation }\end{array}$ \\
$\begin{array}{ll}\text { Research findings: Equivocal or contradictory findings, } \\
\text { sparseness of findings relative to the number and variety of } \\
\text { behaviours, interventions, populations and settings about }\end{array}$ & $\begin{array}{l}\text { Use of machine learning and reasoning algorithms } \\
\text { for evidence synthesis and interpretation. Focus }\end{array}$ \\
$\begin{array}{l}\text { which information is required, complexity of interactions } \\
\text { between intervention components, populations, settings and }\end{array}$ & $\begin{array}{l}\text { associated with the prediction so as to be able to } \\
\text { rigorously incorporate conflicting and missing }\end{array}$ \\
behavioural outcomes & information \\
\hline
\end{tabular}

\section{BEHAVIOUR CHANGE AI SYSTEM}

Here it take an example of artificial intelligence system that developed by IBM Research. The system consists of:

1. To extract automatically the useful information from evaluation reports of behavior change intervention it use Information extraction algorithms and

2. For specific scenarios and predictions about the desired result reasoning algorithms and Machine learning algorithms generate are used to perform inference on the extracted information by generate suggested interventions.

From research reports to extract the useful data both supervised and unsupervised information extraction algorithms are used. Based on a common framework for each information type the algorithms are defined. To define the passage of a text that contains the target value it defines a query for each entity in the unsupervised setting. For example for value of target $=$ passages, participants age contains the word participant and age or year or old. It also adds an integer.

On the basis of defined criteria like the participant's age the answer of candidate should be integer, the answer of candidate extracted from each passage. The ranking of answer is based on proximity. It selected the answer of highest ranking. By using the classifier the query is automatically learnt. This classifiers annotated manually by team of behavioural science. For evaluation this annotations are also used.

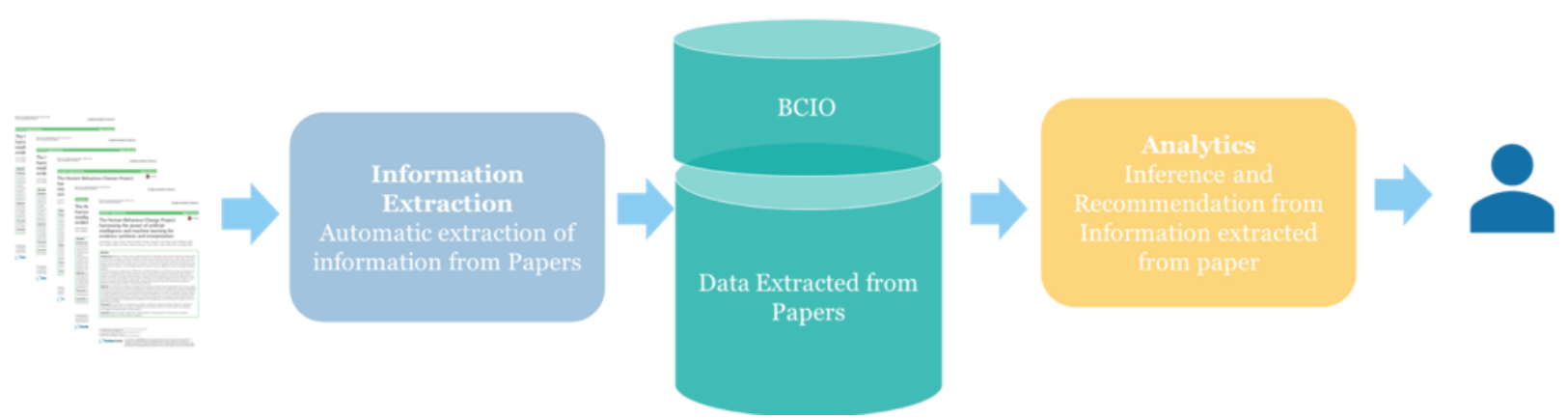

Figure 5: Knowledge System flow

\section{USING DEEP NETWORKS MODELING OF HUMAN STRATEGIC BEHAVIOR}

For analysis and design of multiagent systems Game theory provides a powerful framework. These multiagent systems include some strategic interactions [11]. Example of this type of system is a search engine that use advertising auctions to generate a significant portion of revenue and to optimize and analyze these mechanisms it based on game theoretic reasoning $[11,12]$.

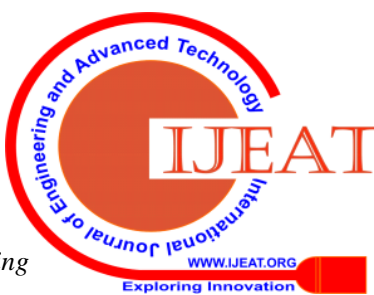


To coordinate the reallocation of valuable radio spectrum the spectrum auctions carefully create the rules of the game and it is based on game theoretic analysis [14]. To analyze the allocation of security personnel security systems are used. In order to optimize their use of scarce resources these security system use as game between rational adversaries [15].

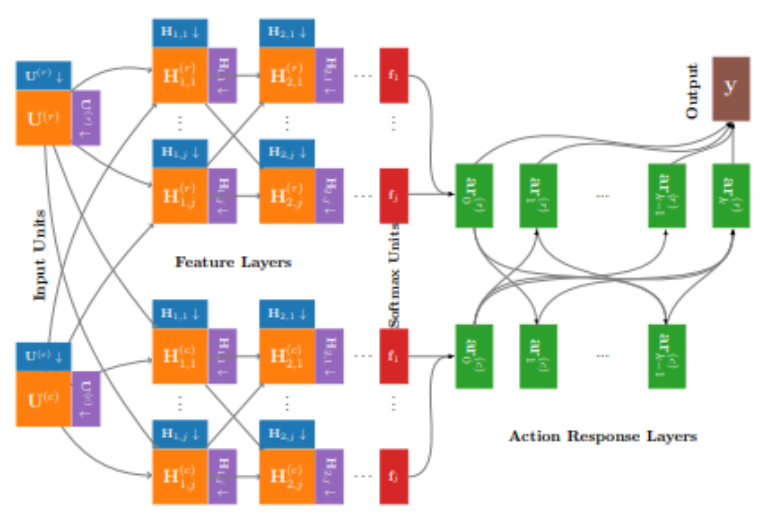

Figure 6: architecture of a schematic representation [16]

To test the performance of a general feed-forward neural network, a natural starting point is applying deep network in a new domain. It needs to flatten the utility values into a single vector of length $\mathrm{mn}+\mathrm{nm}$ to applying this type of model to create normal game. It require a function of learn that maps to the msimplex output by using several layers that are hidden.

\section{CONCLUSION}

The procedure that is use to propel the standard capability that depend upon the past experience is known as machine learning. By using the experiences speculation it makes the numerical model, and its genuine work is to surmise from the models gave. To take the data obviously from the information the philosophy uses computational techniques. To develop a specific profile about an individual, the investigation of looking at the comportment is known as Behavior analysis. At first the Behavior examination is utilized in brain research and for proposing and creating various sorts the application content for client then it created in data innovation. To make the applications for client's close to home needs it turning into another patterns with the utilization of artificial intelligence (AI). in numerous applications like development to do everything from foreseeing purchase practices to modifying a home's indoor controller to the occupant's ideal temperature for a particular time of day use AI and computerized reasoning innovation. To make the $\mathrm{PC}$ so that it can advance without anyone else the AI build up the answer for make oneself working systems. AI is the subcategory of man-made consciousness. To decide the principles that be consolidated to alter programming application by utilizing $\mathrm{AI}$ and man-made consciousness the client's activities and exercises can be examined. It likewise dissects comportment and every day schedule of an individual.

\section{REFERENCES}

1. Ms.D.Pavithra, Dr.A.N.Jayanthi, "A STUDY ON MACHINE LEARNING ALGORITHM IN MEDICAL DIAGNOSIS", International Journal of Advanced Research in Computer Science, Volume 9, No. 4, July - August 2018.

2. Nedelcu, A. (2012, February 09). How To Build a Naive Bayes Classifier. Retrieved from bionicspirit.com: https://www.bionicspirit.com/blog/2012/02/09/howto-buildnaive-bayesclassifier.html.

3. D. Yu, and L. Deng, 2011, "Deep learning and its applications to signal and information processing," IEEE Signal Process. Mag., vol. 28, no. 1 , pp. 145-154.

4. J. Shi and J. Malik,2000, "Normalized cuts and image segmentation," IEEE Transactions on Pattern Analysis and Machine Intelligence, vol. 22, no. 8 , pp. 888-905.

5. A. Kumar, J. Kim, W. Cai, and D. Feng, 2013, "Contentbased medical image retrieval: a survey of applications to multidimensional and multimodality data," J Digit Imaging, vol. 26, no. 6, pp. 1025-1039.

6. N. Tajbakhsh, J. Y. Shin, S. R. Gurudu, R. T. Hurst, C. B. Kendall, M B.Gotway, and J. Liang, 2016, "Convolutional neural networks for medical image analysis: Full training or fine tuning?" IEEE T Med Imaging, vol. 35 , no. 5, pp. 1299- 1312

7. Adriana Albu, Loredana Stanciu, 2016, "Benefits of using artificial intelligence in medical predictions," 1EEE, EHealth and Bioengineering Conference (EHB)

8. M. Abedini, N. C. F. Codella, J. H. Connell, R. Garnavi, M. Merler,S Pankanti, J. R. Smith, and T. Syeda-Mahmood, 2015, "A generalized framework for medical image classification and recognition," IBM J Res Dev, vol. 59 , no. $2 / 3$, pp. 1:1-1:18

9. C. Bishop, 2006, Pattern Recognition and Machine Learning. Springer-Verlag New York.

10. Cherry, K. (n.d.). What Is Behavior Analysis? Retrieved from Psychology.about.com/:

http://psychology.about.com/od/behavioralpsychology/f/behanalysis.htm

11. Y. Shoham and K. Leyton-Brown. Multiagent Systems: Algorithmic Game-theoretic, and Logical Foundations. Cambridge University Press, 2008.

12. B. Edelman, M. Ostrovsky, and M. Schwarz. Internet advertising and the generalized secondprice auction: Selling billions of dollars worth of keywords. The American Economic Review, 97(1), 2007.

13. H. R. Varian. Position auctions. International Journal of Industrial Organization, 25, 2007

14. P. Milgrom and I. Segal. Deferred-acceptance auctions and radio spectrum reallocation. In Proceedings of the Fifteenth ACM Conference on Economics and Computation. ACM, 2014.

15. M. Tambe. Security and Game Theory: Algorithms, Deployed Systems, Lessons Learned. Cambridge University Press, New York, NY, USA, 1st edition, 2011.

16. Jason Hartford, James R. Wright, Kevin Leyton-Brown, "Deep Learning for Predicting Human Strategic Behavior", 30th Conference on Neural Information Processing Systems (NIPS 2016), Barcelona, Spain. 